\title{
Case Report of a Perforated Corneal Tear Traumatic Cataract Sec Esotropia Left Eye in a 12 Years Female Girl
}

\author{
Gowhar Ahmad* \\ Department of ophthalmology, University of Jammu and Kashmir, India \\ *Corresponding author: Gowhar Ahmad, Department of ophthalmology, University of Jammu and Kashmir, India

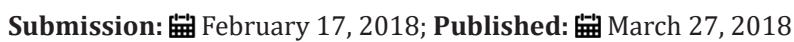

\begin{abstract}
Ocular trauma is a very common disorder which every ophthalmologist faces in the daily routine practice one has to be very vigilant and prompt as far as management of ocular trauma is concerned
\end{abstract}

a) The ocular trauma can be perforating type sustained by Sharpe pointed objects like knife, nails, pencil or pens

b) Blunt trauma due to blow by closed fist or slap or whip lash injury

c) Chemical either acid or alkaline exposure

d) Sports related injury due to cricket ball, hockey ball, tennis ball, base ball, shuttle coke, tennis ball, American football, squash ball, volley ball, golf

e) Road traffic accidents especially motor cycle riders not using helmets

f) Shaken baby syndrome due to injury by waist belts blow by closed fist whip lash injury it is a medico legal problem where the injury can be lacerations of lids conjunctiva, sclera, cornea, hypheama tr, cataract, lamellar, macular hole, retinal tear and retinosciasis

g) Domestic bird injuries like pet birds, hen, parrot, peacock and pigeon. In remote villages when the small children are left in the company of these birds their ids possibility of hen peck injuries of children even corneal perforation is reported

h) Ocular pellet injuries recently pellet induced injuries have occurs in Kashmir pellets are lead bodies which are usually used to hunt birds but they have been used in Kashmir to control mobs and have caused lot of pellet induced ocular injuries

Keywords: Corneal tear; Heamarghe; Hypheama; Traumatic; Cataract; Vitreous; Retinal tear; Lamellar; Macular hole

\section{Introduction}

In recent times management of trauma has become advanced as we have now subspecialties in the field of ophthalmology these days as we have ant segment and post segment surgeon we have paediatric ophthalmologist and oculoplastic surgeon at the same time we have lot of recent advances in the field of ophthalmic microsurgery in the form of most modern ophthalmic instruments and ophthalmic drugs so at present even if we have severely damaged eye all efforts are made to preserve the globe even if a damaged eye may undergo more than 2 operations the main point is that occurrence of sympathetic ophthamia is zero when we look back to past due to this complication for a severely damaged eye the treatment was nucleation because we did not have the modern facilities as we have these days.

\section{Case report}

2 years back a 12 years old female girl sustained a full thickness perforated corneal tear left eye with a nail the full thickness core tear was from 12 to 6 o' clock position initial repair of corneal tear was done with 19 silk sutires in a medical hospital i saw the patient 2 months after first operation on examination there was a linear corneal scar from 12 to 6 o'clock position nicely repaired wund ac well formed no reaction or flare pupil was distorted with presence of traumatic cataract and 25 degrees esotropia i did lesectomy with sclera supported pc oil and after a gap of 2 months i did operation for esotropia cosmetic squint correction of 25 degrees esotropia $5 \mathrm{~mm}$ recession of medial rectus and $7 \mathrm{~mm}$ resection of lateral rectus isolation of medial rectus was done by conjunctiva wing exposure $5 \mathrm{~mm}$ recession of medial rectus was done and position of muscle 
was secured on sclera using 6 zero vicoryl suture similar exposure of lateral rectus was done and $7 \mathrm{~mm}$ resection of lateral rectus was done conctiva was reposted back postoperative period was satisfactory.

\section{Discussion}

The girl underwent three operation her visual and cosmetic outlook is very satisfactory even though 3 operations were done her vision is 624 and eye is almost straight

\section{Conclusion}

In conclusion as already mentioned we try to save the most severely damaged eyes due to recent advances in ophthalmology provided the patient is treated in time and by proper consultant.

\section{References}

1. Oum BS, Lee JS \& Han YS (2004) Clinical features of ocular trauma in emergency department. Korean j Ophthalmol 18(1): 70-78.

1. Kaimbo WK, Spileers W \& Missotten L (2002) Ocular emergencies in Kinshasa (Democratic Republic of Congo). Bull soc Belge ophtalmol 284: 49-53.

2. Hamill MB (2002) Corneal and scleral trauma. Ophthamol Clin North Am 15(2): 185-194.
3. Xie L, Zhai h, Dong X \& Shi W (2008) primary diseases of corneal perforation in Shandong province china a 10 tears retrospective study. Am J Ophthalmol 145(4): 662-666.

4. Omobolanie AA \& Henrietta N (2012) Pattern of paediatric corneal laceration injuries in the university of Port Harcourt teaching hospital rivers state, Nigeria BMC res notes 5: 683.

5. Liu ML, Chang YS, Tseng SH, Cheng HC, Huang FC, et.al (2010) paediatric ocular Trauma in Taiwan. J paediatrophthalmol strabismus 47(2): 8895.

6. Ariturk N \& Sahin M (1999) Oge l et turkj padiatr. 41: 43-52.

7. Alfaro DV \& Jablon EP (2005) Rodriguez fontal $m$ et al fishing related ocular trauma. Am J Ophthalmol 139(3): 488-492.

8. Kumar M, Arora R, Sanga L \& Sota LD (1999) Scleral-fixated iol in unilateral aphakic children. Ophthalmology 106(11): 2184-2189.

9. Scott IU, Plynn HW \& Feuer W (1995) Endophthalmitis after secondary iol. A case-report study. Ophthalmology 102(12): 1925-1931.

10. Sewelam A (2003) Four-point fixation of post chamber iol in children with unilateral aphakia. J Cataract Surg 29(2): 294-300.

11. Chipont EM, Garcia-Henmoosa P \& Alio JL (2001) Reversal of myopic anisonetropic amblyopi with phakic iol implantation. J Refract Sur 17(4): 460-462. (c) (i) Creative Commons Attribution 4.0 International License

For possible submissions Click Here

\section{Submit Article}

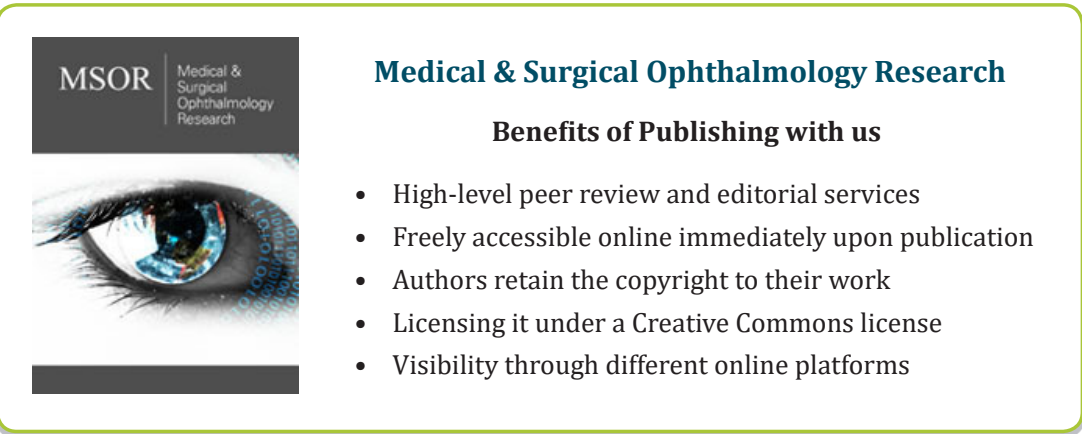

